\title{
ORIGINAL ARTICLE \\ Evaluation of the Walking Index for Spinal Cord Injury II (WISCI-II) in children with Spinal Cord Injury (SCI)
}

\author{
C Calhoun Thielen ${ }^{1}$, C Sadowsky ${ }^{2}$, LC Vogel ${ }^{3}$, H Taylor ${ }^{4}$, L Davidson ${ }^{5}$, J Bultman ${ }^{6}, \mathrm{~J} \mathrm{Gaughan}^{1}$ and MJ Mulcahey ${ }^{1}$
}

Study Design: Mixed methods were used in this study. The appropriateness of the levels of the Walking Index for Spinal Cord Injury II (WISCI-II) for application in children was critically reviewed by physical therapists using the Modified Delphi Technique, and the interand intra-rater reliability of the WISCI-II in children was evaluated.

Objectives: To examine the construct validity, and to establish reliability of the WISCI-II related to its use in children with spinal cord injury $(\mathrm{SCl})$.

Setting: United States of America.

Methods: Using a Modified Delphi Technique, physical therapists critically reviewed the WISCI-II levels for pediatric utilization. Concurrently, ambulatory children under age 18 years with $\mathrm{SCl}$ were evaluated using the WISCI-II on two occasions by the same therapist to establish intra-rater reliability. One trial was photographed and de-identified. Each photograph was reviewed by four different physical therapists who gave WISCI-II scores to establish inter-rater reliability. Summary and descriptive statistics were used to calculate the frequency of yes/no responses for each WISCI-II level question and to determine the percent agreement for each question. Inter- and intra-rater reliability was calculated using interclass correlation coefficients (ICCS) with 95\% confidence intervals (CI).

Results: Construct validity was confirmed after one Delphi round during which at least $80 \%$ agreement was established by 51 physical therapists on the appropriateness of the WISCI-II levels for children. Fifty-two children with SCI aged 2-17 years completed repeated WISCI-II assessments and 40 de-identified photographs were scored by four physical therapists. Intra- and inter-rater reliability was high $(\mathrm{ICC}=0.997, \mathrm{Cl}=0.995-0.998$ and $\mathrm{ICC}=0.97, \mathrm{Cl}=0.95-0.98$, respectively).

Conclusion: This study demonstrates support for the use of the WISCI-II in ambulatory children with SCI.

Sponsorship: This study was funded by the Craig H Neilsen Foundation, Spinal Cord Injury Research on the Translation Spectrum, Senior Research Award \#282592 (Mulcahey, PI).

Spinal Cord (2017) 55, 478-482; doi:10.1038/sc.2016.142; published online 18 October 2016

\section{INTRODUCTION}

Ambulation is often a primary goal of the individual who sustains a spinal cord injury (SCI), and therefore, one of the primary objectives of SCI rehabilitation research is to develop and evaluate strategies to restore motor function, especially ambulation. Key to rehabilitation research is the availability of psychometrically sound instruments and outcome measures. The National Institute of Neurologic Disorders and Stroke provides a common data element structure, which includes classification of outcome measures, relative to use in SCI research. ${ }^{1}$ The Walking Index for Spinal Cord Injury II (WISCI-II) is a diseasespecific instrument designed to evaluate functional mobility and gait. $^{2-5}$ It is recommended for SCI clinical trials that define ambulation and functional mobility as end points. ${ }^{6-8}$

The WISCI-II is an ordinal scale (0-20) consisting of 21 items reflecting various levels of walking ability, taking into account the use of assistive devices, orthotic devices and physical assistance (Table 1). The individual being assessed walks $10 \mathrm{~m}$ (32.8 feet), ${ }^{9}$ which is a distance often correlated with household ambulation. ${ }^{10}$ The WISCI-II was developed by a multidisciplinary team specializing in SCI (clinical and research physicians and physical therapists) from international spinal cord injury centers and then further modified. ${ }^{2,9}$ The utility of the WISCI-II has been established in the adult population with SCI, and it demonstrates good validity and reliability. ${ }^{3-5,9}$

It is important to use valid and reliable measures for clinical care and in clinical trials involving children with SCI so that comparisons may be made over time, across centers and trials, thus showing linkages between pediatric and adult SCI outcomes. Despite being classified as a supplemental instrument for studies with children (https://commondataelements.ninds.nih.gov/SCI.aspx\#tab = Data_Standards), only one pilot study has examined the psychometric properties of the WISCI-II in a pediatric sample. ${ }^{11}$ This pilot study conducted by Calhoun et al. ${ }^{11}$ focused on evaluating the reliability of the WISCI-II when used with children with SCI. Intra- and inter-rater reliability of repeated WISCI-II scores in this study was high in children aged 4-16 years. Despite these strong findings, limitations of this pilot work include a small sample size of 10 subjects and single site

${ }^{1}$ Department of Occupational Therapy, Jefferson College of Health Professions, Thomas Jefferson University, Philadelphia, PA, USA; ${ }^{2}$ International Center for Spinal Cord Injury, Kennedy Krieger Institute, Baltimore, MD, USA; ${ }^{3}$ Shriners Hospitals for Children, Chicago, IL, USA; ${ }^{4}$ TIRR Memorial Hermann, Houston, TX, USA; ${ }^{5}$ Shriners Hospitals for Children, Sacramento, CA, USA and ${ }^{6}$ Mary Freebed Rehabilitation Hospital, Grand Rapids, MI, USA

Correspondence: C Calhoun Thielen, Department of Occupational Therapy, Jefferson College of Health Professions Thomas Jefferson University, 901 Walnut Street, 6th Floor, Philadelphia, PA 19107, USA.

E-mail: Christina.Thielen@jefferson.edu

Received 23 May 2016; revised 12 September 2016; accepted 14 September 2016; published online 18 October 2016 
Table 1 WISCI-II level and description

\begin{tabular}{|c|c|}
\hline Level & Description \\
\hline 0 & $\begin{array}{l}\text { Client is unable to stand and/or participate } \\
\text { in assisted walking }\end{array}$ \\
\hline 1 & $\begin{array}{l}\text { Ambulates in parallel bars, with braces and } \\
\text { physical assistance of two persons, }<10 \mathrm{~m}\end{array}$ \\
\hline 2 & $\begin{array}{l}\text { Ambulates in parallel bars, with braces and } \\
\text { physical assistance of two persons, } 10 \mathrm{~m}\end{array}$ \\
\hline 3 & $\begin{array}{l}\text { Ambulates in parallel bars, with braces and } \\
\text { physical assistance of one person, } 10 \mathrm{~m}\end{array}$ \\
\hline 4 & $\begin{array}{l}\text { Ambulates in parallel bars, no braces and } \\
\text { physical assistance of one person, } 10 \mathrm{~m}\end{array}$ \\
\hline 5 & $\begin{array}{l}\text { Ambulates in parallel bars, with braces and } \\
\text { no physical assistance, } 10 \mathrm{~m}\end{array}$ \\
\hline 6 & $\begin{array}{l}\text { Ambulates with walker, with braces and } \\
\text { physical assistance of one person, } 10 \mathrm{~m}\end{array}$ \\
\hline 7 & $\begin{array}{l}\text { Ambulates with two crutches, with braces } \\
\text { and physical assistance of one person, } 10 \mathrm{~m}\end{array}$ \\
\hline 8 & $\begin{array}{l}\text { Ambulates with walker, no braces and } \\
\text { physical assistance of one person, } 10 \mathrm{~m}\end{array}$ \\
\hline 9 & $\begin{array}{l}\text { Ambulates with walker, with braces and } \\
\text { no physical assistance, } 10 \mathrm{~m}\end{array}$ \\
\hline 10 & $\begin{array}{l}\text { Ambulates with one cane/crutch, with braces } \\
\text { and with physical assistance of one person, } 10 \mathrm{~m}\end{array}$ \\
\hline 11 & $\begin{array}{l}\text { Ambulates with two crutches, no braces } \\
\text { and physical assistance of one person, } 10 \mathrm{~m}\end{array}$ \\
\hline 12 & $\begin{array}{l}\text { Ambulates with two crutches, with braces } \\
\text { and no physical assistance, } 10 \mathrm{~m}\end{array}$ \\
\hline 13 & $\begin{array}{l}\text { Ambulates with walker, no braces and } \\
\text { no physical assistance, } 10 \mathrm{~m}\end{array}$ \\
\hline 14 & $\begin{array}{l}\text { Ambulates with one cane/crutch, no braces } \\
\text { and physical assistance of one person, } 10 \mathrm{~m}\end{array}$ \\
\hline 15 & $\begin{array}{l}\text { Ambulates with one cane/crutch, with braces } \\
\text { and no physical assistance, } 10 \mathrm{~m}\end{array}$ \\
\hline 16 & $\begin{array}{l}\text { Ambulates with two crutches, no braces and } \\
\text { no physical assistance, } 10 \mathrm{~m}\end{array}$ \\
\hline 17 & $\begin{array}{l}\text { Ambulates with no devices, no braces and } \\
\text { physical assistance of one person, } 10 \mathrm{~m}\end{array}$ \\
\hline 18 & $\begin{array}{l}\text { Ambulates with no devices, with braces and } \\
\text { no physical assistance, } 10 \mathrm{~m}\end{array}$ \\
\hline 19 & $\begin{array}{l}\text { Ambulates with one cane/crutch, no braces } \\
\text { and no physical assistance, } 10 \mathrm{~m}\end{array}$ \\
\hline 20 & $\begin{array}{l}\text { Ambulates with no devices, no braces and } \\
\text { no physical assistance, } 10 \mathrm{~m}\end{array}$ \\
\hline
\end{tabular}

study. Therefore, the purpose of this study was to examine the construct validity of the WISCI-II as a gait and functional mobility scale for children, and to establish reliability of WISCI-II scores in a larger and more diverse sample of children with SCI, and across multiple pediatric facilities across the nation.

\section{MATERIALS AND METHODS}

Mixed methods were used to evaluate the WISCI-II in children with SCI. First, the WISCI-II scale and individual items were exposed to content expert evaluation using an electronic survey (construct validity). Then the scores from repeated administrations were used to establish inter- and intra-rater reliability of the WISCI-II in children.

\section{Construct validity}

A survey that listed each of the 21 WISCI-II levels (Table 1) with the same corresponding question for each level, 'Is this an appropriate item for children' was developed to examine construct validity. In addition, one final question was asked regarding the sequencing of the items for pediatric SCI, 'Does the ranking of the items reflect a logical hierarchy from unable to ambulate to independent with ambulation in pediatric SCI?' For all questions, participants were given a yes/no response option, and asked to provide an explanation for each 'no' answer. Using the Modified Delphi Technique, ${ }^{12}$ an iterative review of modified items was planned until $80 \%$ of responders agreed that the items and sequence were appropriate for children.

Purposeful and snowball sampling were used to recruit survey participants. Specifically, physical therapists known to the investigators were e-mailed an invitation that included a description of the study purpose and a link to the survey. The e-mail asked physical therapist volunteers to complete the survey and forward the invitation to their physical therapist colleagues. The survey was available for access and completion for a 3-week period and completed in an anonymous manner. Survey responses were collected using a data entry program that was automatically submitted by the respondent upon completion. In this way, all responses were de-identified in the database.

Participants also reported the number of total years in practice, the number of years in pediatric practice, the number of years in SCI practice and experience with the WISCI-II.

\section{Reliability}

A convenience sample of ambulatory children with chronic SCI under the age of 18 years was identified from six pediatric SCI rehabilitation centers across the nation. An estimated number of 30-50 ambulatory children were planned on the basis of the feasibility of recruiting ambulatory children with SCI. Children were included if they had the ability to ambulate reciprocally, and parental and child consent was obtained. Children were excluded if they had a comorbidity impairing motor function or if there was unwillingness to participate as evidenced by refusal to provide written consent. Because of the age of all participants, written parental consent was obtained for all subjects by their parent/legal guardian. Children aged 7-17 years also provided written assent.

For intra-rater reliability, each child underwent two trials of ambulation, separated by at least $1 \mathrm{~h}$ and not more than $24 \mathrm{~h}$, with the same therapist. The maximal WISCI-II level for each ambulation trial was determined by the therapist using the Walking Index for Spinal Cord Injury II (WISCI-II): Instructions for Use (http://www.spinalcordcenter.org/research/wisci_ii_guide_revised2012Aug22.pdf). Participants ambulated on a smooth, non-slippery surface of $10 \mathrm{~m}$ using braces or equipment as necessary. Each study therapist underwent training on the WISCI-II with an expert/developer of the WISCI-II. Training included a presentation on the development of the WISCI-II, and review of the measure levels, descriptions and standardization for testing and scoring. Training also used example cases to practice scoring and to establish consistency across therapists.

Each subject who completed $10 \mathrm{~m}$ was photographed during one of the WISCI-II trials; the photo captured braces, devices and/or physical assistance the child required during the trial. For inter-rater reliability, each photograph was scored by four physical therapists who were not involved in data collection. The physical therapist who scored the photographs also reported the number of total years in practice, the number of years in pediatric practice, the number of years in SCI practice and experience with the WISCI-II.

\section{Data analysis}

To analyze content validity data, summary and descriptive statistics were used to calculate the frequency of yes/no responses for each WISCI-II level question and to determine the percent agreement for each question. The content of the comments and open-ended questions were analyzed to identify ways in which the scale could be improved for children and to summarize salient points about the WISCI-II for pediatric therapists to consider.

All data were de-identified and entered into a secure master spreadsheet. Intra- and inter-rater reliabilities were calculated using intraclass correlation coefficients (ICC) and 95\% confidence intervals (CI). For inter-rater reliability, the ICC model used was $(2,1)$, and the ICC model used for intra-rater reliability was $(3,1) \cdot{ }^{13}$ 
Table 2 Sample of physical therapists for the Delphi Method Technique round 1

\begin{tabular}{|c|c|c|c|c|c|c|c|}
\hline \multirow{2}{*}{$\begin{array}{l}\text { Total physical therapist } \\
\text { participants } \mathrm{N}(\%)\end{array}$} & \multicolumn{4}{|c|}{ Years of experience $\mathrm{N}(\%)$} & \multicolumn{2}{|c|}{ Number (\%) therapist with experience } & \multirow[t]{2}{*}{ Number (\%) experience with WISCI-II } \\
\hline & $<2$ & $2-5$ & $6-10$ & $>10$ & Pediatric & Pediatric and/or adult SCl rehabilitation & \\
\hline $51(100)$ & $5(9.80)$ & 17 (33.33) & $12(23.52)$ & 17 (33.33) & 39 (76.47) & $47(92.16)$ & $22(43.14)$ \\
\hline
\end{tabular}

Abbreviations: N, number; \%, percentage.

Table 3 Survey results using the Modified Delphi Technique demonstrating construct validity and at least $80 \%$ agreement

\begin{tabular}{|c|c|c|}
\hline WISCI-Il level & $\begin{array}{c}\% \text { of physical therapists who agreed the } \\
\text { item/level is appropriate for children }\end{array}$ & Rationale for 'No' responses at each WISCI-II level \\
\hline 0 & 95.4 & Depends on age limit; appropriate over 9 months but not under \\
\hline 1 & 81.4 & $\begin{array}{l}\text { Not many smaller size patients require assistance of } 2 \text {; parallel bars } \\
\text { may scare children or not go low enough }\end{array}$ \\
\hline 2 & 83.7 & $\begin{array}{l}\text { Not many smaller size patients require assistance of } 2 \text {; parallel bars may } \\
\text { intimidate children or not go low enough }\end{array}$ \\
\hline 3 & 93.0 & Parallel bars may intimidate children or not go low enough \\
\hline 4 & 92.9 & Parallel bars may intimidate children or not go low enough \\
\hline 5 & 92.9 & Parallel bars may intimidate children or not go low enough \\
\hline 6 & 83.3 & $\begin{array}{l}\text { Rolling posterior walkers are often used with pediatrics, standard walker is not appropriate for } \\
\text { children, definition of 'walker' is not how it is set up for children, children often use wheels on } \\
\text { a walker, expanding type of walker defined would make more appropriate for children }\end{array}$ \\
\hline 7 & 95.4 & Children under 5 are often unable to use crutches \\
\hline 8 & 80.9 & $\begin{array}{l}\text { Rolling posterior walkers are often used with pediatrics, standard walker is not appropriate for } \\
\text { children, definition of 'walker' is not how it is set up for children, children often use wheels on } \\
\text { a walker, expanding type of walker defined would make more appropriate for children }\end{array}$ \\
\hline 9 & 81.4 & $\begin{array}{l}\text { Rolling posterior walkers are often used with pediatrics, standard walker is not appropriate for } \\
\text { children, definition of 'walker' is not how it is set up for children, children often use wheels on } \\
\text { a walker, expanding type of walker defined would make more appropriate for children }\end{array}$ \\
\hline 10 & 97.6 & Cane are not used with young children \\
\hline 11 & 95.2 & Children under 5 years are often unable to use crutches, type of crutches could be a factor \\
\hline 12 & 97.6 & Children under 5 years are often unable to use crutches, type of crutches could be a factor \\
\hline 13 & 88.3 & $\begin{array}{l}\text { Rolling posterior walkers are often used with pediatrics, standard walker is not appropriate for } \\
\text { children, definition of 'walker' is not how it is set up for children, children often use wheels on } \\
\text { a walker, expanding type of walker defined would make more appropriate for children }\end{array}$ \\
\hline 14 & 95.1 & Cane are not used with young children \\
\hline 15 & 97.7 & Cane are not used with young children \\
\hline 16 & 97.7 & Children under 5 years are often unable to use crutches, type of crutches could be a factor \\
\hline 17 & 97.7 & No responses \\
\hline 18 & 100 & No responses \\
\hline 19 & 97.7 & Cane are not used with young children \\
\hline 20 & 100 & No responses \\
\hline $\begin{array}{l}\text { Ranking of all items reflect a } \\
\text { logical hierarchy for children }\end{array}$ & 81.4 & $\begin{array}{l}\text { Frequently in pediatrics you see a progression of decreased assistive device, but not with the } \\
\text { bracing; if only bracing is decreased it is not reflected in the scale; I would think with } \mathrm{SCl} \text { the } \\
\text { child relies more on braces for foot placement than on physical assistance; need kid friendly } \\
\text { language to take willingness and motivation into consideration; level of assistance may not be } \\
\text { reflected for a very small child; it is uncommon to progress a child to a cane; kids do not stick } \\
\text { to a true hierarchy; small children may cruise or hold on to furniture as opposed to parallel } \\
\text { bars; parallel bars may not be intuitive for training small children }\end{array}$ \\
\hline
\end{tabular}

\section{Statement of ethics}

The Institutional Review Board at all six pediatric rehabilitation centers approved this study.

\section{RESULTS}

Construct validity

Sample characteristics of the 51 physical therapists who responded to the electronic survey as content experts are provided in Table 2. As shown in Table 3, there was at least $80 \%$ agreement that each WISCIII level was appropriate for children. A summary of the comments and feedback provided by the respondent is in Table 3 .

\section{Reliability}

Fifty-two children with SCI, aged 2-17 years, completed repeated WISCI-II assessments. Characteristics of the participant sample are shown in Table 4. Intra-rater reliability of scores for maximal WISCI- 
II level was high ( $\mathrm{ICC}=0.99-1.00, \mathrm{CI}=0.97-1.00)$ for all comparisons including the total sample ( $\mathrm{ICC}=0.99, \mathrm{CI}=0.995-0.998)$, by ASIA Impairment Scale (AIS) (ICC $=1.00)$, and by age groups $(\mathrm{ICC}=1.00)$.

Of the 52 subjects, 40 had photographs. All 4 physical therapists who scored the photographs had greater than 10 years of experience, 2 (50\%) had pediatric experience, all $4(100 \%)$ had pediatric and/or adult SCI rehabilitation experience and 1 (25\%) had experience with the WISCI-II. Inter-rater reliability of maximum WISCI-II scores was high $(\mathrm{ICC}=0.97, \mathrm{CI}=0.95-0.98)$.

\section{DISCUSSION}

In this study, we demonstrated that the levels and sequencing of the WISCI-II are appropriate for children with chronic SCI aged 2-17 years, and that the intra- and inter-rater reliability of the maximal WISCI-II score is high when determined by trained physical therapists. These results provide psychometric support for use of the WISCI-II in pediatric clinical studies. This is critical as both clinicians and researchers should be using validated measures that are appropriate for the pediatric SCI population, have utility, and when possible can align pediatric and adult practice. Alignment of pediatric and adult practice is necessary for longitudinal monitoring of children into adulthood.

An important finding about the validity of the WISCI-II levels relative to pediatrics was that the physical therapists readily agreed that the levels were appropriate for children, and therefore no levels were dropped. For levels that did not receive 100\% agreement, feedback focused on the WISCI-II descriptions of standardized equipment and the fact that children may use different assistive devices and require different forms of physical assistance. As an example, WISCI-II items at Levels 1 and 2 are described as 'ambulation in the parallel bars with the assistance of two people'. Smaller children may not require assistance or two people and may not be able to use the parallel bars unless they have the ability to adjust very low. WISCI-II items at Levels $6,8,9$ and 13 are described as ambulation using a walker. The WISCIII Instructions for Use explicitly describe a walker as 'Walkers should be conventional; but if a rolling walker is used, it should be coded as a walker and identified in the descriptors'. This type of conventional walker may not always be appropriate for children and it is used less than with adults. Children often use a rolling type walker with wheels in a posterior configuration as opposed to anterior. The items of the WISCI-II Levels 1, 2, 6, 8, 9 and 13 all had agreement between 80 and $90 \%$, whereas all other WISCI-II levels had agreement $>90 \%$. To summarize, there was a strong agreement among therapists that the item content and scoring is appropriate for children, but it may need to be modified slightly to address pediatric needs, as described in Table 2. One such modification may include expanding the definition of walker to include a posterior rolling walker.

The youngest participant in this study was 2 years of age, which is 6-12 months from the 12-18-month age a child typically starts to ambulate. The three 2-year-old participants were able to follow the directions necessary to complete the assessment. Because of the wide variation that is typical in growth and development, it is possible that a child younger than 2 years of age could complete this assessment based on their motivation and understanding of the task. Likewise, it is also possible that a child older than 2 years of age may not be able to participate. There were a total of eight participants who were between 3 and 4 years of age. Because all eight participants were able to understand the directions and complete the WISCI-II, we believe that by at least 3 years of age, all children should be able to participate in WISCI-II testing.
Table 4 Demographics and SCl characteristics of child participants

\begin{tabular}{ccc}
\hline Subjects & $N(\%)$ for intra-rate relia- \\
bility of total sample & $N(\%)$ for inter-rater \\
reliability
\end{tabular}

\begin{tabular}{lll}
\hline Gender & & \\
Male & $22(42.3)$ & $16(40.0)$ \\
Female & $30(57.7)$ & $24(60.0)$
\end{tabular}

Ethnicity

Hispanic $\quad 8(15.4) \quad 5(12.5)$

Non-Hispanic $\quad 44(84.6) \quad 35(87.5)$

Race

Caucasian

African-American $7(13.5) \quad 6(15.0)$

$\begin{array}{lll}\text { Asian } & 0(0) & 0(0)\end{array}$

Native American/Alaska $\quad 0(0) \quad 0(0)$

Native

$\begin{array}{lll}\text { Native Hawaiian/other } & 0(0) & 0(0)\end{array}$

Pacific Islander

Other

$3(5.7)$

$2(5.0)$

\section{Age groups \\ $0-5$ \\ 6-12 \\ 13-15 \\ $16-17$}

$12(23.1)$

$8(20.0)$

$25(48.1)$

$21(52.5)$

$6(11.5)$

$5(12.5)$

$9(17.3)$

$6(15.0)$

$\begin{array}{lcc}\begin{array}{l}\text { Neurological level } \\ \text { C1-C4 }\end{array} & 5(9.6) & 3(7.5) \\ \text { C5-C8 } & 2(3.8) & 2(5.0) \\ \text { T1-S5 } & 24(46.2) & 18(45.0) \\ \text { Unknown a } & 21(40.4) & 17(42.5) \\ \text { Diagnosis } & & \\ \text { Tetraplegia } & 14(26.9) & 11(27.5) \\ \text { Paraplegia } & 38(70.1) & 29(72.5) \\ \text { AlS } & & \\ \text { A } & 3(5.7) & 2(5.0) \\ \text { B } & 3(5.7) & 2(5.0) \\ \text { C } & 9(17.3) & 8(20.0) \\ \text { D } & 16(30.8) & 12(30.0) \\ \text { Unknown } & 21(40.4) & 16(40.0)\end{array}$

Time since injury

$\begin{array}{lcc}<1 \text { year } & 6(11.5) & 0(0) \\ 1-5 \text { years } & 28(53.9) & 24(60.0) \\ 6-10 \text { years } & 16(30.8) & 14(35.0) \\ 11-15 \text { years } & 2(3.8) & 2(5.0)\end{array}$

Abbreviations: AIS, ASIA impairment scale; $\mathrm{N}$, number.

${ }^{a}$ Neurological level and AIS were unable to be determined due to the participant's young age and developmental inability to complete the International Standards for Neurological Classification of Spinal Cord Injury examination.

One limitation of this study is the short time interval between the repeated administrations of the WISCI-II. It is possible that therapists could recall their score on the first trial. This short duration was chosen to accommodate patients who were undergoing rehabilitation to ensure no real change occurred between the two trials and based on the feasibility of conducting repeated trials in an outpatient environment. However, even with this limitation, the reliability results of this 
study are comparable to those reported in the one pediatric pilot study ${ }^{11}$ and to those reported in an adult study. ${ }^{5}$

Another limitation of this study is the use of photographs to score the WISCI-II as opposed to video recording. Using photographs, the assumption had to be made that the participant ambulated the $10 \mathrm{~m}$.

Future work is needed to establish the responsiveness of the WISCIII in children, which would also potentially enable calculation of effect size and values for the minimal clinically important differences to aid in interpretation of changed scores.

\section{CONCLUSION}

This study demonstrates and supports the use of the WISCI-II in children with spinal cord injury. Although salient points unique to pediatrics may need to be considered, the WISCI-II, as designed, can be used with children as young as 2 years of age.

\section{DATA ARCHIVING}

There were no data to deposit.

\section{CONFLICT OF INTEREST}

The authors declare no conflict of interest.

\section{ACKNOWLEDGEMENTS}

This study was funded by the Craig H Neilsen Foundation, Spinal Cord Injury Research on the Translation Spectrum, Senior Research Award \#282592 (Mulcahey, PI). The authors would like to acknowledge the unnamed physical therapists who participated in the validity survey. We would also like to acknowledge the study therapists who recruit, enroll and complete study data collection, including Jennifer Silvestri, Julie Cagney, Lauren White, Rebecca Martin, Jennifer Schottler, Kristine Higgins, Ingrid Parry and Jennifer Mazurkiewicz, as well as Mary Schmidt-Read for training the study therapists. Lastly, we would like to acknowledge the four physical therapists who scored the photographs, Susan Wainwright, Therese Johnston, Stephanie Muth and Louis Hunter.

1 Grinnon ST, Miller K, Marler JR, Lu Y, Stout A, Odenkirchen J et al. National Institute of Neurological Disorders and Stroke Common Data Elements Projects - approach and methods. Clin Trials 2012; 9: 322-329.

2 Ditunno PL, Ditunno JF Jr. Walking index for spinal cord injury (WISCI-II): scale revision. Spinal Cord 2001; 39: 654-656.

3 Ditunno JF Jr, Barbeau H, Dobkin BH, Elashoff R, Harkema S, Marino RJ et al. Validity of the walking scale for spinal cord injury and other domains of function in a multicenter clinical trial. Neurorehabil Neural Repair 2007; 21: 539-550.

4 van Hedel HJ, Wirz M, Dietz V. Assessing walking ability in subjects with spinal cord injury: validity and reliability of 3 walking tests. Arch Phys Med Rehabil 2005; 86: 190-196.

5 Marino RJ, Scivoletto G, Patrick M, Tamburella F, Read MS, Burns AS et al. Walking index for spinal cord injury version 2 (WISCI-II) with repeatability of the 10- $\mathrm{m}$ walk time: inter- and intrarater reliabilities. Am J Phys Med Rehabil 2010; 89: 7-15.

6 Alexander MS, Anderson KD, Biering-Sorensen F, Blight AR, Brannon R, Bryce TN et al. Outcome measures in spinal cord injury: recent assessments and recommendations for future directions. Spinal Cord 2009; 47: 582-591.

7 Anderson K, Aito S, Atkins M, Biering-Sorensen F, Charlifue S, Curt A et al. Functional recovery measures for spinal cord injury: an evidence based review for clinical practice and research. J Spinal Cord Med 2008; 31: 133-144.

8 Steeves JD, Lammertse D, Curt A, Fawcett JW, Tuszynski MH, Ditunno JF et al. Guidelines for the conduct of clinical trials for spinal cord injury (SCI) as developed by the IC-CP panel: clinical trial outcome measures. Spinal Cord 2007; 45: 206-221.

9 Ditunno JF Jr, Ditunno PL, Graziani V, Scivoletto G. Bernardi M, Castellano V et al. Walking index for spinal cord injury (WISCI): an international multicenter validity and reliability study. Spinal Cord 2000; 38: 234-243.

10 Catz A, Itzkovich M, Agranov E, Ring H, Tamir A. SCIM - spinal cord independence measure: A new disability scale for patients with spinal cord lesions. Spinal Cord 1997; 35: 850-856.

11 Calhoun CL, Mulcahey MJ. Pilot study of reliability and validity of the Walking Index for Spinal Cord Injury II (WISCl-II) in children and adolescents with spinal cord injury. J Ped Rehabil Medi 2012; 5: 275-279.

12 Dalkey NC. In: Studies in the Quality of Life (eds Dalkey NC, Rourke DI, Lewis R, Snyder D) Lexington Books: Lexington MA, USA, 1972.

13 Shrout PE, Fleiss JL. Intraclass correltations: uses in assessing the rater reliability. Psychol Bull 1979; 86: 420-428. 